\title{
Sequential Studies of Healing in Endothelial Seeded Vascular Prostheses: Histologic and Ultrastructure Characteristics of Graft Incorporation
}

\author{
William E. Burkel, Ph.D., David W. Vinter, M.S., John W. Ford, B.A., \\ Raymond H. Kahn, Ph.D., Linda M. GrahaM, M.D., \\ and James C. Stanley, M.D.
}

Departments of Anatomy and Surgery, University of Michigan Medical School, Ann Arbor, Michigan 48109

Presented at the Annual Meeting of the Association for Academic Surgery, Birmingham, Alabama, November $5-8,1980$

\begin{abstract}
Chronological events leading to incorporation of endothelial cell seeded prosthetic vascular grafts were documented in this investigation. Forty-one adult dogs underwent thoracoabdominal bypass using double-velour Dacron grafts. Experimental grafts were preclotted with blood containing enzymatically derived endothelium immediately after derivation, or after 14 days of cultivation. Control grafts were preclotted without addition of endothelial cells. Grafts were studied grossly as well as by light, scanning electron, transmission electron, and fluorescence microscopy, 1 to 28 days postimplantation. Control graft healing proceeded from pannus and perigraft ingrowth. Experimental grafts healed from seeded cells as well. Platelets covered all grafts by Days 1 and 2 . Thrombus accumulations on control grafts, first evident on Day 4, became maximal by Day 14 . Seeded grafts appeared relatively thrombus free with patches of endothelial cells noted by 4 days. These cells were initially separated by gaps, often containing leukocytes. Endothelium became densely packed with cellular migration and proliferation. Subendothelial tissues were composed of fibrin and smooth muscle. Control and experimental grafts were approximately 10 and $80 \%$ endothelialized, respectively, by Day 28. Smooth muscle dominated subintimal tissue in experimental grafts. These cells initially appeared fibroblastoid. Endothelial seeding enhances both pseudointimal development and rapid graft incorporation.
\end{abstract}

During the past 20 years numerous investigators have endeavored to improve the performance of vascular prostheses by seeding cells or tissue fragments into them [2]. Recently, Herring and his colleagues demonstrated that tissue stripped from veins with steel-wool pledgets and subsequently seeded into vascular prostheses during graft preclotting enhanced development of an endothelial lining [11]. We have previously reported on techniques resulting in endothelialization of long vascular grafts using enzymatically derived autologous endothelial cells for graft seeding either immediately after isolation [9] or after cultivation for 2 weeks [10]. The present report documents in detail the cellular and ultrastructural character of vascular graft incorporation and healing following seeding with endothelial cells in a canine experimental model.

\section{METHODS}

Forty-one 23- to 30-kg dogs underwent thoracoabdominal bypass grafting. Twentyfive prostheses were seeded with autologous endothelial cells (experimental grafts) during the preclotting process (Fig. 1) and 16 were preclotted without endothelium (control grafts).

Endothelial cell isolation. Endothelial cells were obtained from external jugular veins. Veins were carefully exposed, tributaries ligated, and a $12-\mathrm{cm}$ segment was removed from each side of the neck. The segments were immediately everted over 5-mm-diameter stainless-steel rods, tied in place with sutures, and transported to the tissue culture laboratory in cold Hanks' calcium- and magnesium-free balanced salt solution (CMFBSS). After a brief wash in CMF-BSS they 


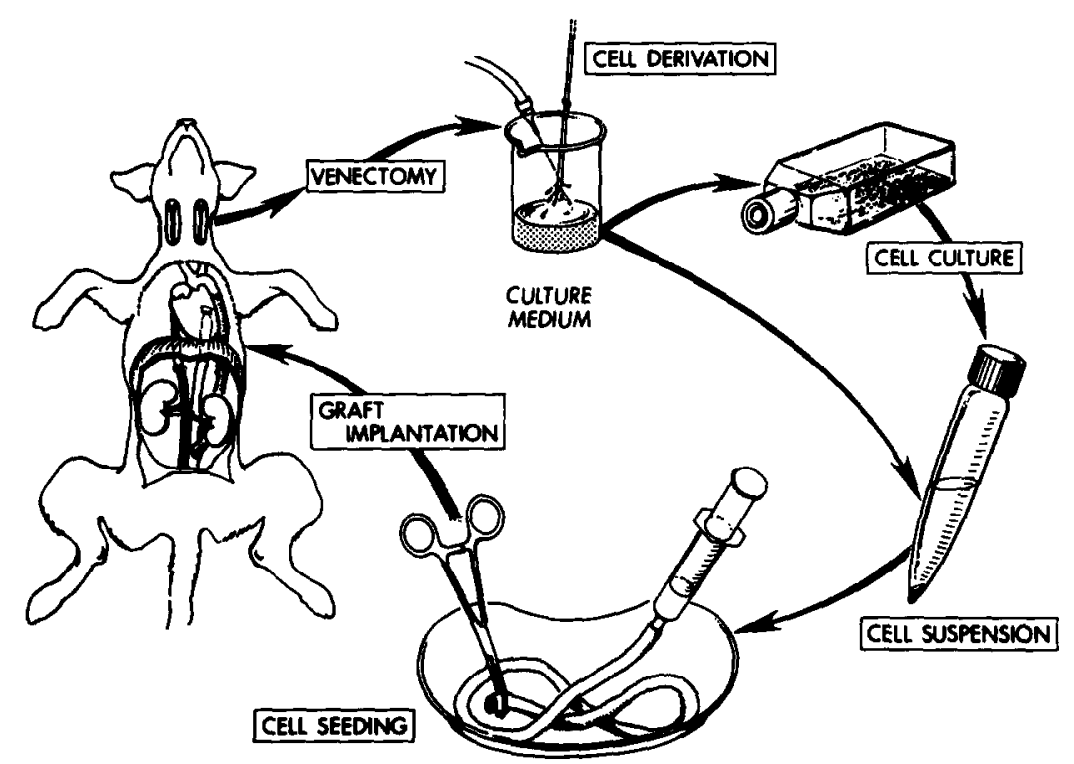

Fig. 1. Methodology for producing endothelial cell-lined vascular grafts: (1) external jugular veins are aseptically removed, everted over a rod and transported to the tissue culture laboratory; (2) after incubation in trypsin, EDTA, and collagenase, cells are washed from the vein with a stream of tissue culture medium; (3) derived cells may be cultivated for 2 weeks and then trypsinized to provide a cell suspension, or immediately used after derivation; (4) the suspension is mixed with autologous blood and forced through the graft walls to seed cells; and (5) the seeded graft is implanted.

were incubated at $37^{\circ} \mathrm{C}$ in $0.1 \%$ trypsin and $0.125 \%$ EDT A in CMF-BSS, at pH 8.0, and then in $0.5 \%$ collagenase in BSS with calcium and magnesium at $\mathrm{pH} 7.4$, for $10 \mathrm{~min}$ each. Vein segments were then washed with a jet of Eagle's Basal Medium (BME). This produced a suspension of both single cells and clumps of up to 30 cells each $[3,6]$. These cells were centrifuged to obtain a pellet, washed in BME, recentrifuged, and subsequently resuspended in BME. An aliquot was removed for hemocytometer counting. Since the accuracy of the hemocytometer depends upon even distribution of cells, and since harvested endothelial cells were frequently in clumps, the total number of individual cells, though carefully counted, was somewhat imprecise. Depending upon the size of the vein and efficiency of the harvest, approximately 0.5 to $1.5 \times 10^{6}$ cells were obtained from each vein. Harvested cells, not used for counting, were either returned to the surgery suite in cold BME or placed in culture for 2 weeks. Although smooth muscle cells were seldom observed in the cell suspensions, presumably some were present in all harvests.

Cell culture. After harvesting, cells from each vein were placed in individual tissue culture flasks (Falcon T-25). Cells were cultivated in BME with $28 \mathrm{mM}$ Hepes $(N-2$ hydroxyetholpiperizine $N^{\prime}$-2-ethanesulfonic acid) buffer, $1.5 \mathrm{~g} /$ liter of sodium bicarbonate, $50 \mathrm{mg} /$ liter of gentamicin sulfate, and $10 \%$ autologous serum at $\mathrm{pH} 7.2$. Cells were cultivated for 14 days at $37^{\circ} \mathrm{C}$, with the nutrient BME changed every 2 to 3 days. After cultivation the monolayer of endothelium was removed from flasks using a solution of $0.5 \%$ trypsin and $0.2 \%$ EDTA in CMFBSS and resuspended in three $0.5 \mathrm{ml}$ aliquots of culture medium for seeding experimental grafts. Approximately 0.5 to 3.0 $\times 10^{6}$ cells were available for seeding each graft using this methodology [10].

Seeding and implantation of grafts. Dogs were anesthetized with $30 \mathrm{mg} / \mathrm{kg}$ sodium pentobarbital, intubated, and mechanically ventilated. Penicillin benzathine and procaine hydrochloride, 450,000 units each, 


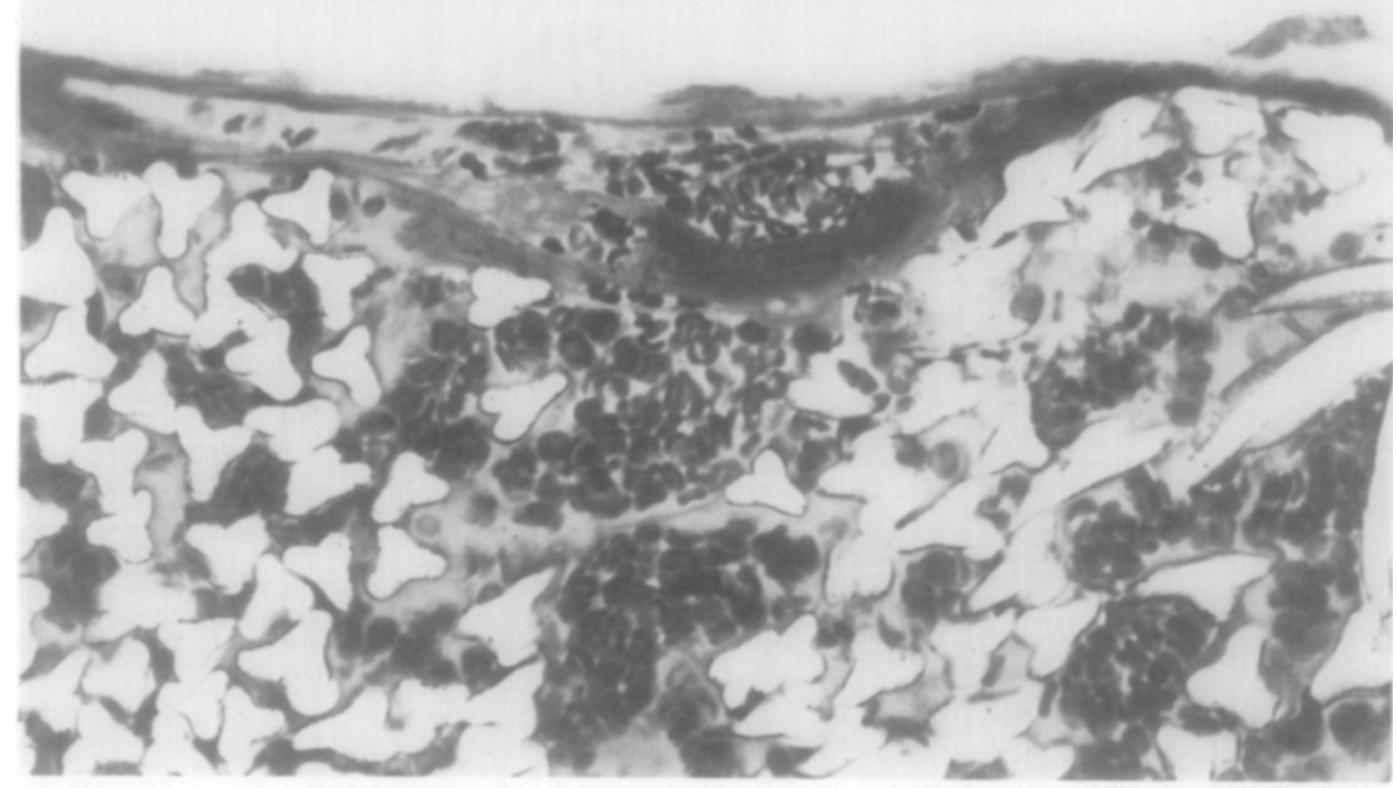

FIG. 2. Section of a preclotted graft at the time of implantation. The interstices are filled with RBCs enmeshed in a fibrin matrix. The luminal surface is composed of fibrin, platelets, and RBCs $(\times 400)$.

were administered preoperatively. Hydration was maintained during the procedure by intravenous administration of $15 \mathrm{ml} / \mathrm{kg} / \mathrm{hr}$ of lactated Ringer's solution. Grafts used in this investigation were double-velour Dacron, $6 \mathrm{~mm}$ i.d. and 25 to $30 \mathrm{~cm}$ in length (Meadox Medical No. 113306). They were implanted as thoracoabdominal bypasses,

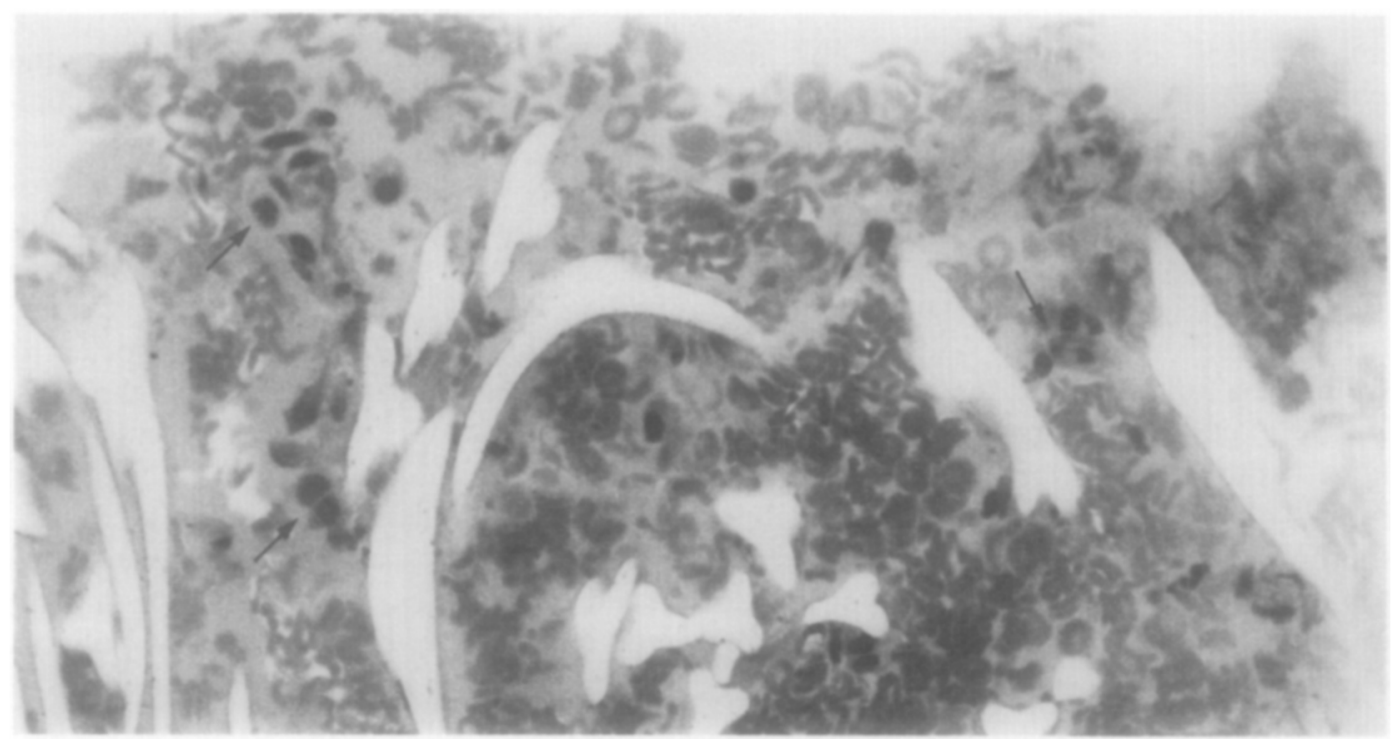

FIG. 3. Section of a graft seeded with endothelial cells immediately following their derivation. Several small clumps of endothelial cells (arrows) are evident. Interestingly, most endothelial clumps are near the outer surface of the graft $(\times 300)$. 


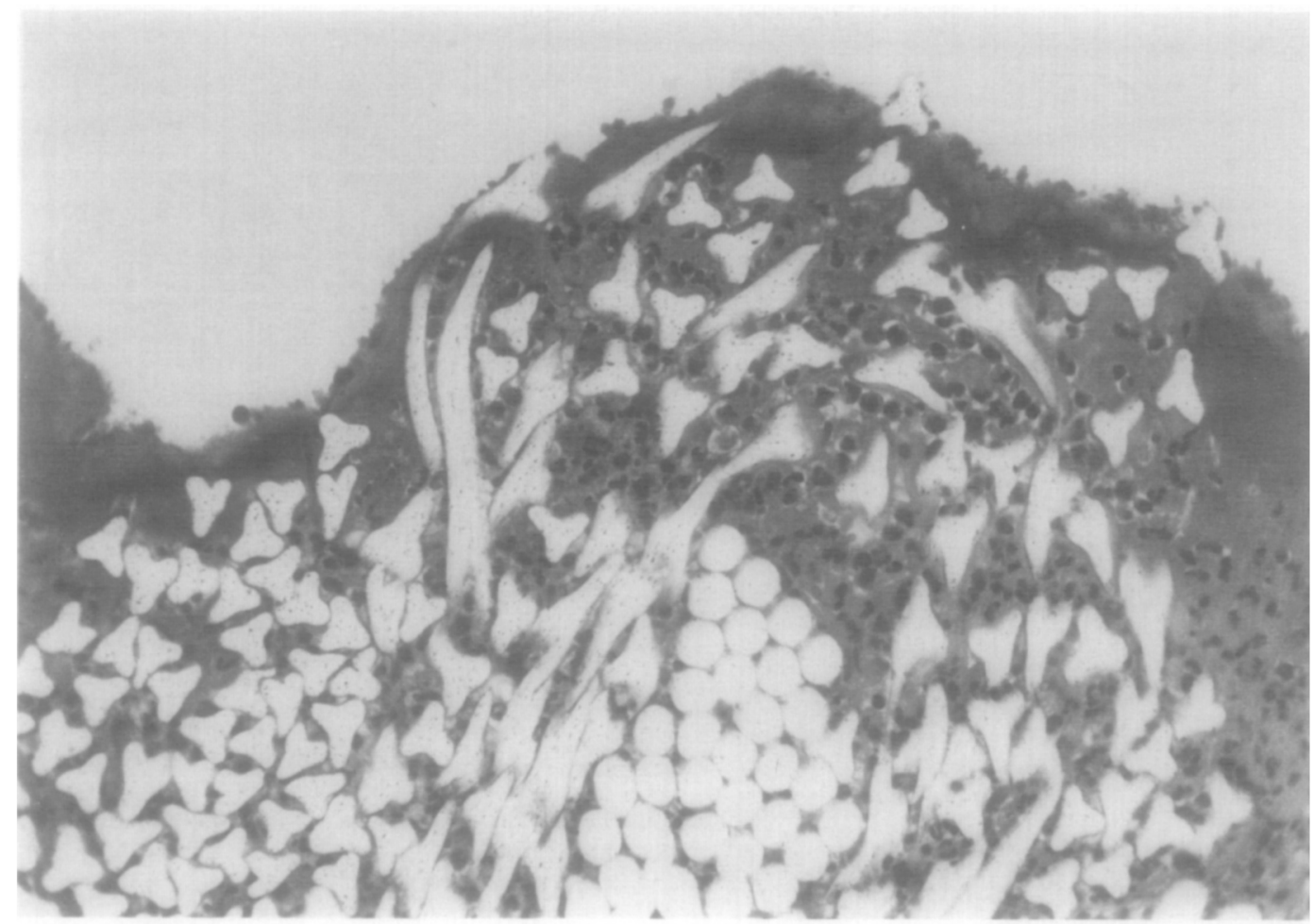

FIG. 4. Section of 1-day implant revealing a luminal surface (above) covered with a thin layer of platelets and WBCs. The RBCs have lysed and a narrow acellular zone of fibrin and platelets forms the inner surface of the graft. Large numbers of WBCs have migrated into the graft from the blood and perigraft tissue $(\times 300)$.

anastomosed end-to-end proximally and end-to-side distally using 4-O polyproylene suture [15]. The distal stump of the thoracic aorta was oversewn.

Prior to anastomosis, grafts were preclotted in a four-step procedure [25]. Three 10-ml aliquots of freshly drawn caval blood, to which $0.5 \mathrm{ml}$ of $\mathrm{BME}$ had been added were used for the first three clotting steps. In the experimental grafts this BME contained autologous endothelial cells that had been derived immediately prior to preclotting, or which had been cultivated in vitro for 2 weeks. A fourth aliquot of blood, $15 \mathrm{ml}$ in volume and containing 5000 units of sodium heparin, was used to flush the graft as the final step of preclotting. Grafts were implanted immediately after preclotting with care taken to prevent drying. Dogs were systemically anticoagulated with 100 units $/ \mathrm{kg}$ of sodium heparin prior to undertaking the thoracic aortic anastomosis. Following completion of this anastomosis the heparin was neutralized by injection of $1.0 \mathrm{mg} / \mathrm{kg}$ of protamine sulfate. The entire procedure, including isolation of endothelium for immediate seeding, took approximately $3 \mathrm{hr}$.

Graft harvest and evaluation. In order to study early as well as late events in the healing process, grafts were studied from 1 to 28 days postimplantation. Of grafts seeded with cultivated endothelium, four dogs were sacrificed at 2 weeks, and four dogs were sacrificed at 4 weeks. In those grafts having endothelium derived immediately prior to seeding, two dogs were sacrificed on Days 2, 4 , and 7, four dogs were sacrificed on Days 1 and 28 , and three dogs were sacrificed on Day 14. Two unseeded control grafts were examined on Days 2 and 7, and three other 


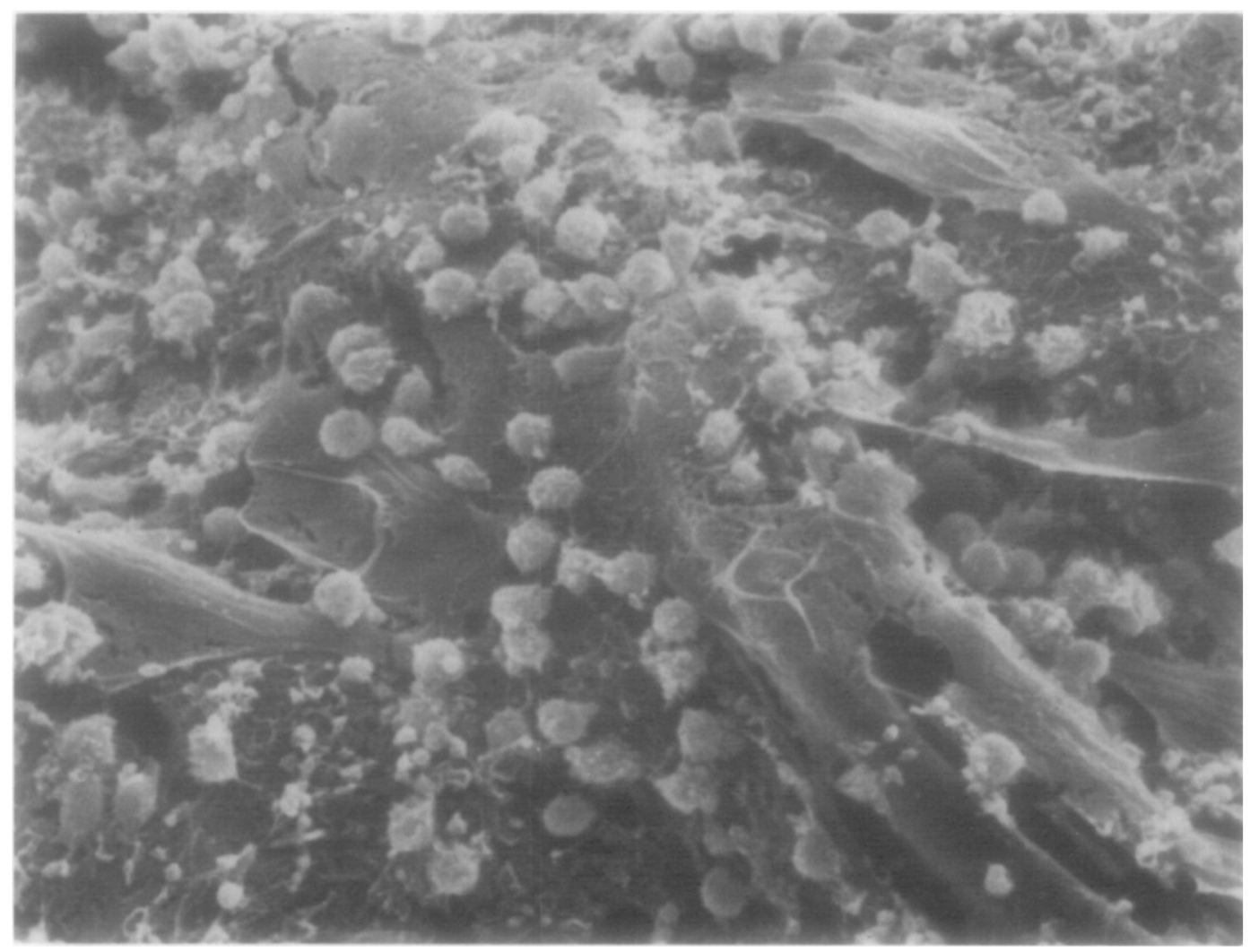

FIG. 5. Scanning electron micrograph of luminal surface of a 4-day seeded graft. Endothelial cells are apparent for the first time (center). Most of the graft is covered with WBCs, platelets, and fibrin. Control grafts have the same appearance, but lack endothelial cells (SEM $\times 1400)$.

grafts were evaluated on Days 1, 4, 14, and 28. Prior to graft removal animals received 150 units sodium heparin to prevent thrombus formation during graft isolation and excision. Grafts were immediately flushed and immersed in physiologic saline for $35-\mathrm{mm}$ color photography. Representative samples of each graft were fresh-frozen or fixed in $2.5 \%$ glutaraldehyde in $0.1 M$ sodium cacodylate. Frozen samples were subsequently used for fluorescent studies with factor VIIIrelated antigen to verify the presence of endothelium [10]. Glutaraldehyde-fixed tissue was embedded in glycol methacrylate for light microscopy and in Epon for transmission electron microscopy. Methylene bluebasic fuchsin was used to stain tissue for the light-microscopic studies. Samples for scanning electron microscopy were dehy- drated in ethanol, critical-point-dried in $\mathrm{CO}_{2}$, and sputter-coated with gold.

\section{RESULTS}

All grafts were patent when removed. There was great variation in gross appearance related to the healing process. When implanted all of the grafts were infiltrated with blood cells and fibrin by the preclotting procedure (Fig. 2). By Day 1 the luminal surfaces, except for small focal areas, were nearly free of thrombus. At Day 2 the experimental seeded grafts remained whitish, while in the unseeded control grafts the small focal thrombi appeared to be diminished. By Day 4 an increase of thrombi on the surface of control grafts was again apparent. This progressed through Day 7 , reaching a maximum at Day 14. After 14 days control 


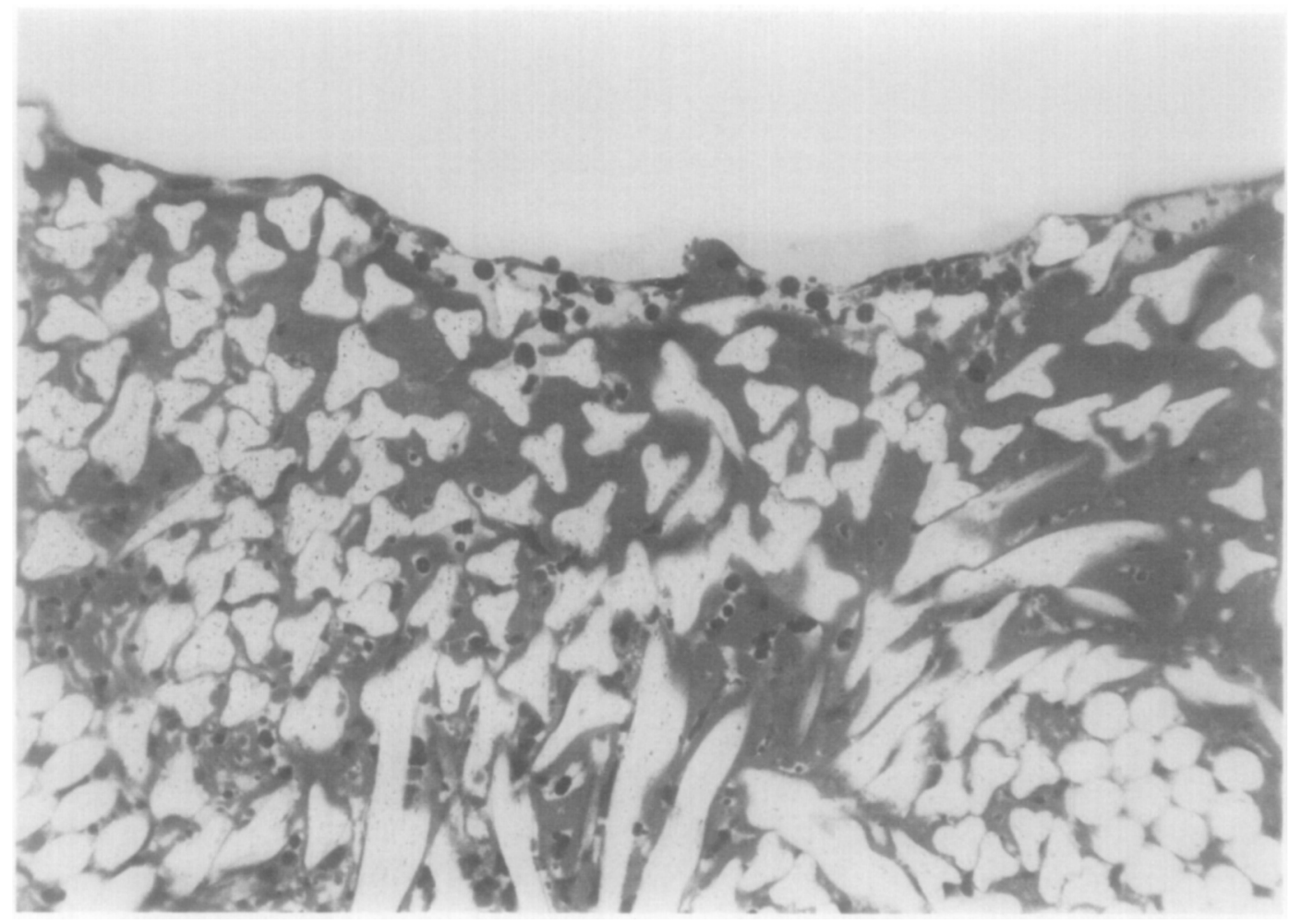

FIG. 6. Section of a 4-day seeded graft. Note the thin monolayer of endothelial cells on the luminal surface (above). An acellular layer of fibrin separates the endothelium from the deeper part of the graft which exhibits WBCs in various stages of lysis. The fibrin immediately subjacent to endothelium has been lysed, presumably by fibrinolysins from endothelial cells. The immature endothelial surface is frequently studded with WBCs (see Figs. 5 and 7) that migrate between cells, through the lysed zone, and into the fibrin $(\times 300)$.

grafts demonstrated a diminution of frank red thrombus. The latter was replaced by a fibrin coagulum. Experimental grafts remained free of thrombus, except for focal areas, throughout the time intervals studied. Experimental grafts, however, did exhibit an increase of thrombus through the 7-and 14-day periods, but remained significantly free of thrombus in comparison to control grafts $[10]$.

Cells involved in the healing and incorporation of control grafts are derived from three sources. Platelets, monocytes, and polymorphs, as well as fibrin, accumulate from the blood. Fibroblasts, fibroelastic connective tissue, blood vessels, and blood cells forming the outer capsule of the graft arise from the surrounding retroperitoneal connective tissue, serosal and adventitial surfaces of adjacent organs, and their vasculature. The third source of cells comes from the host vessel by means of pannus ingrowth. This consists primarily of smooth muscle and endothelial cells, but also includes fibroblasts. In addition, experimental grafts have cells seeded during preclotting that proliferate within the graft itself.

Preclotted grafts. Immediately following preclotting, grafts are totally infiltrated with blood cells entrapped in a fibrin matrix. RBCs and WBCs are included in the proportions found in normal blood. Fibrin was found primarily on the flow surface but strands were seen enmeshing RBCs and WBCs throughout. White blood cells were scattered randomly within the graft, with 


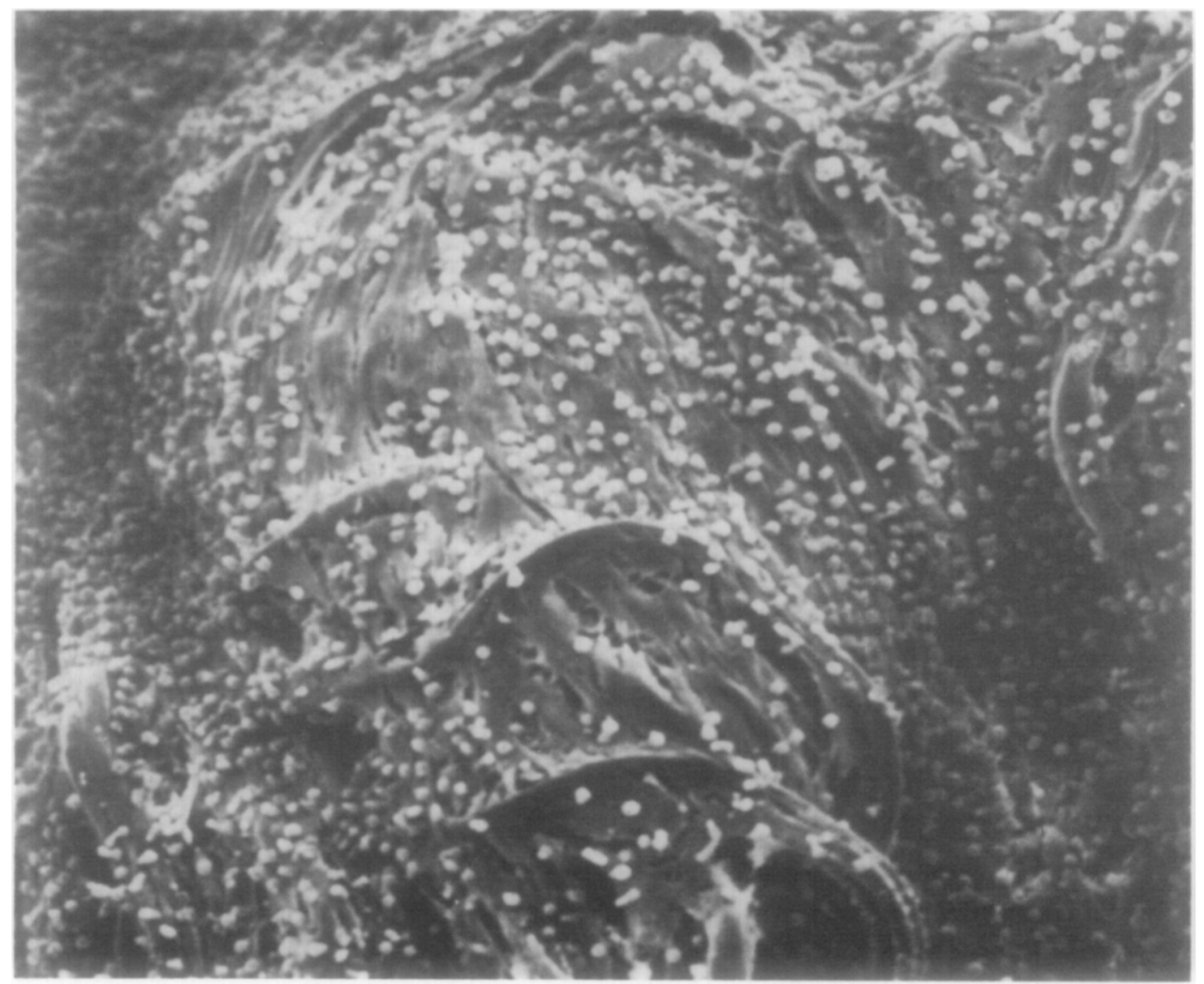

FIG. 7. The luminal surface of a 7-day seeded graft showing a large patch of endothelium. At this stage small gaps are still apparent between endothelial cells and WBCs are frequently found in association with these gaps (see Fig. 8) $($ SEM $\times 350)$.

platelets attached to both fibrin and graft fibers. In most specimens of preclotted experimental and control grafts there were no identifiable differences. Endothelial cells in grafts seeded with cultured cells were not visible immediately after preclotting. This may reflect the fact that trypsinization produces a suspension of single cells that are difficult to distinguish from WBCs. In grafts preclotted with noncultured cells derived immediately prior to seeding, clumps of endothelium were occasionally observed (Fig. 3).

One-day grafts. The inner surface of Day 1 grafts consisted of a thin platelet carpet with scattered white blood cells (Fig. 4). The WBCs (polymorphs predominantly) ap- pear to have infiltrated from perigraft tissue and the luminal surface into the graft. Despite the fact that WBCs were found on the graft surface and penetrated toward the exterior, a narrow zone, 100 to $150 \mu \mathrm{m}$ below the surface, contained almost exclusively fibrin and platelets. Almost all RBCs had lysed and were no longer visible in light micrographs. Endothelial cells were not evident on the graft surfaces and were difficult to identify between graft fibers in either the immediately seeded or cultured cell-seeded grafts.

Two-day grafts. The surfaces of the Day 2 control and experimental grafts were similar to Day 1 surfaces. Unseeded grafts displayed the same type surface throughout all of the 


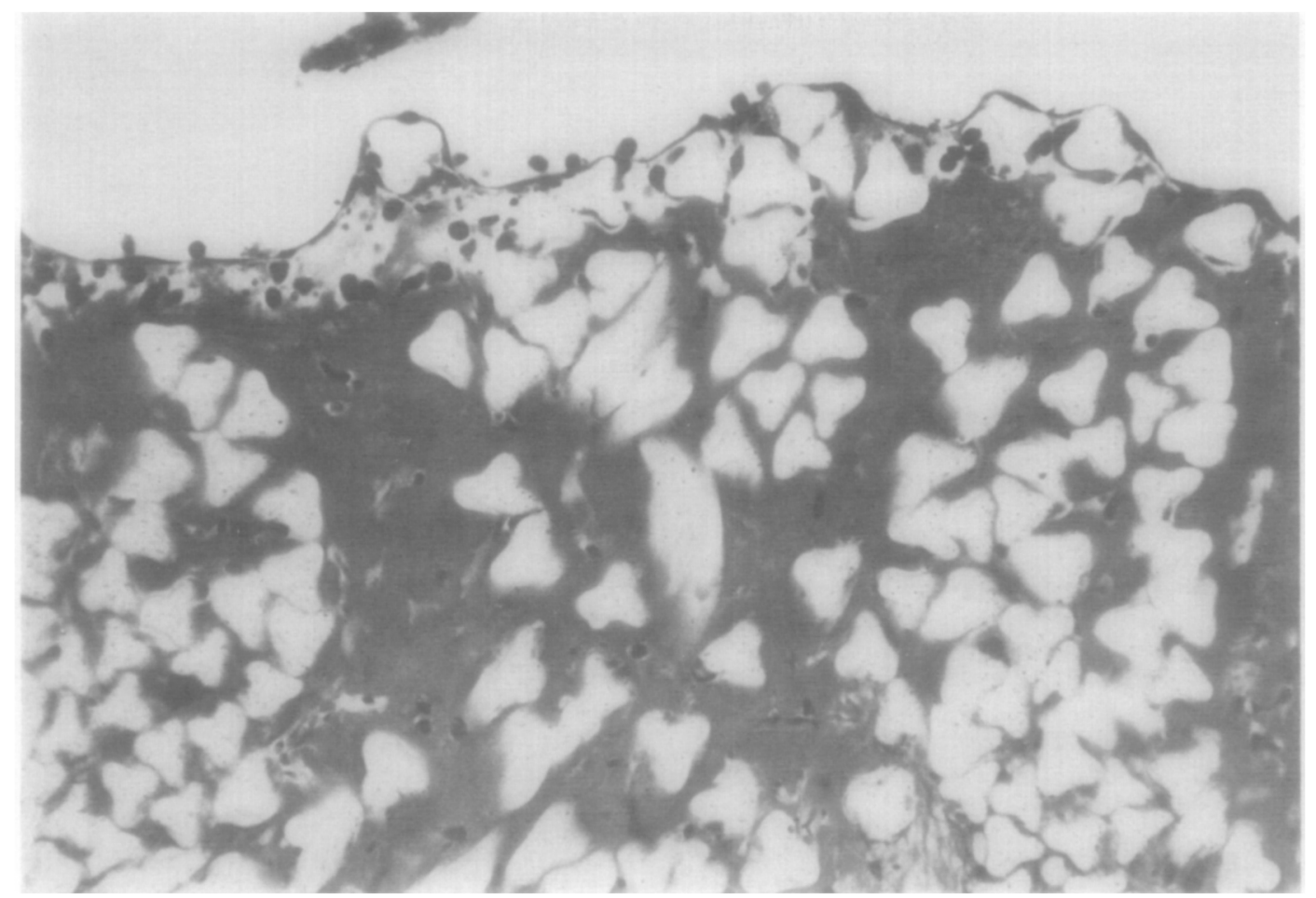

FIG. 8. A section of a 7-day seeded graft showing continued growth of the endothelial surface. The fibrin immediately subjacent to the endothelium has been lysed allowing endothelial cells to lie directly on the surface of the graft fibers. A zone of fibrin still persists between the surface and the deeper part of the graft where WBCs predominate. The lysed zone contains WBCs and other cells that will proliferate to form the subendothelial tissue $(\times 300)$.

time intervals, the only difference occurring in areas where fresh thrombus accumulated periodically. The fibrin zone immediately beneath the surface remained, although by this time many of the platelets had lysed. Deeper within the graft many WBCs were in stages of lysis, and RBCs were not seen. In some areas, WBCs were seen migrating through the fibrin.

Four-day grafts. Experimental and control grafts at Day 4 exhibited few gross differences, although there may have been a slightly greater amount of thrombus on the surface of the controls. The control surface remained similar to those of Days 1 and 2, being composed of platelets, fibrin, and WBCs. The zone of fibrin and platelets immediately below the surface of the grafts remained, and WBCs were observed migrat- ing through it. White blood cell infiltration from the exterior of the graft also continued at this stage. Experimental, seeded grafts showed the first signs of endothelialization at Day 4 (Fig. 5). Small areas of endothelium surrounded by platelets and fibrin were observed throughout the graft. The cells in these areas were very immature. They lacked tight junctional complexes between them and had no underlying basal lamina. The endothelium consisted of a monolayer stretching between graft fibers (Fig. 6). The fibrin immediately beneath the growing endothelium had lysed, leaving a clear area, perhaps filled with fluid and containing many WBCs above the more dense fibrin. White blood cells were observed penetrating gaps between the new endothelial cells and entering this lucent space. Areas between the 


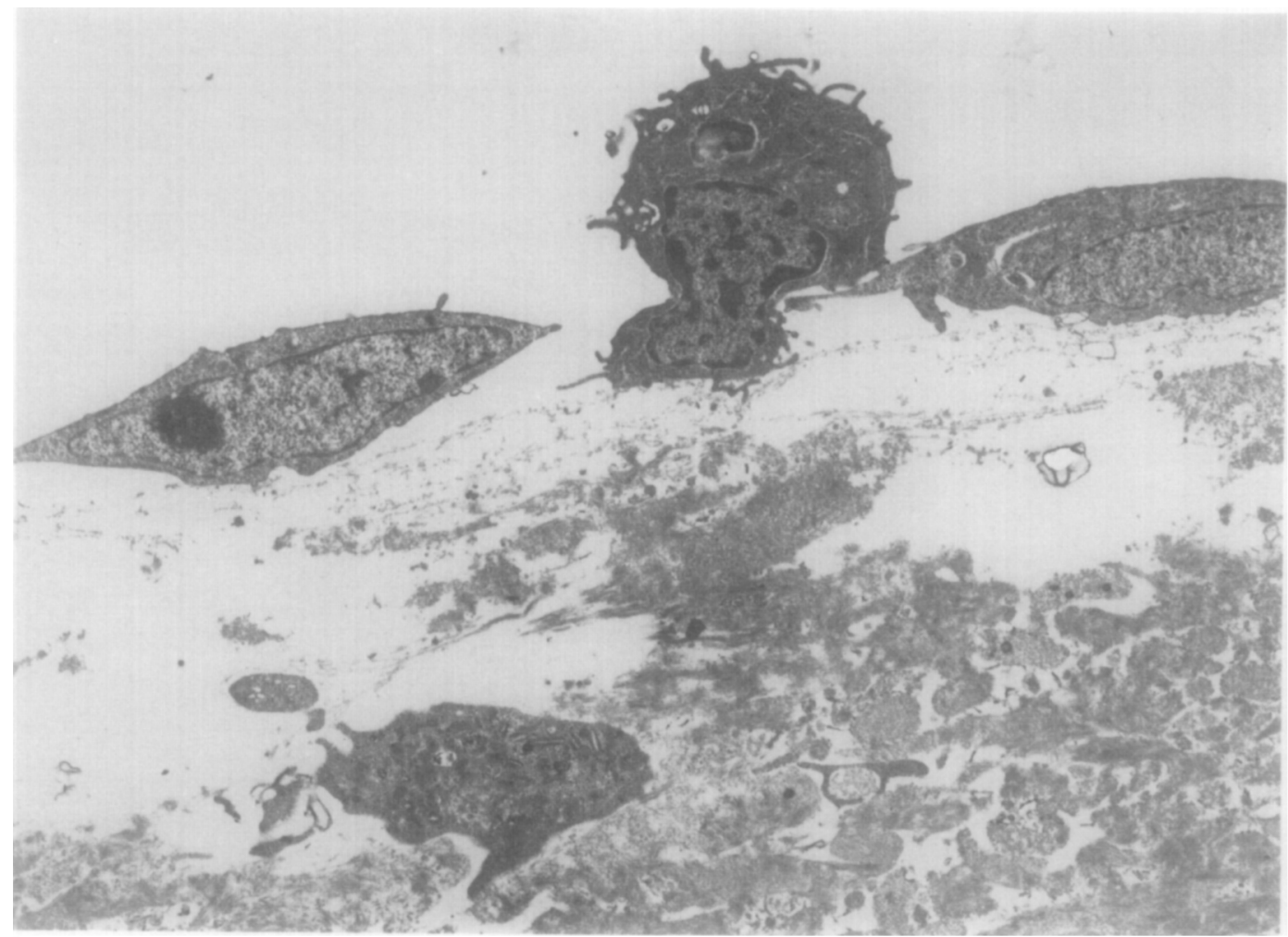

FIG. 9. Transmission electron micrograph of newly endothelialized region of a 7-day seeded graft. At this stage the two endothelial cells are still migrating over the surface and have not as yet established close contacts with one another, or with the underlying substrate. A zone of lysed fibrin lies immediately beneath the cells separating them from the denser fibrin below. A WBC is in the process of passing between the cells and through the tenuous matrix to which they are attached (TEM $\times 6700$ ).

endothelial patches appeared identical to control surfaces. Growth from the exterior of the graft continued with evidence of early connective tissue infiltration.

Seven-day grafts. By Day 7 control grafts were beginning to accumulate a considerable amount of fresh thrombus. This was especially the case in the valleys between graft crimps. Seeded grafts, in comparison to those of Day 4 accumulated slightly more reddishness on their internal surface. The control surface continued to consist of fibrin, platelets, and WBCs. In experimental grafts the endothelial patches had enlarged, but exhibited little other difference from findings at Day 4 (Fig. 7). The centers of these patches generally lacked WBCs on the surface, while at the periphery the WBCs were seen penetrating gaps between endothelial cells (Figs. 8 and 9). Connective tissue continued to grow from the exterior, and foreign body giant cells were apparent among the outer graft fibers. The most rapid incorporation of the graft appeared in those areas where graft fibers were more closely packed together. Here cells were seen migrating between the graft fibers toward the surface. In regions where graft fibers were more widely separated, the healing process lagged and fibrin and platelets predominated.

Fourteen-day grafts. Control grafts at Day 14 exhibited the most gross thrombus, covering about $75 \%$ of the luminal surface. Areas not covered with thrombus had the same appearance as in earlier grafts. The fibrin and thrombus layer was of variable thickness, 


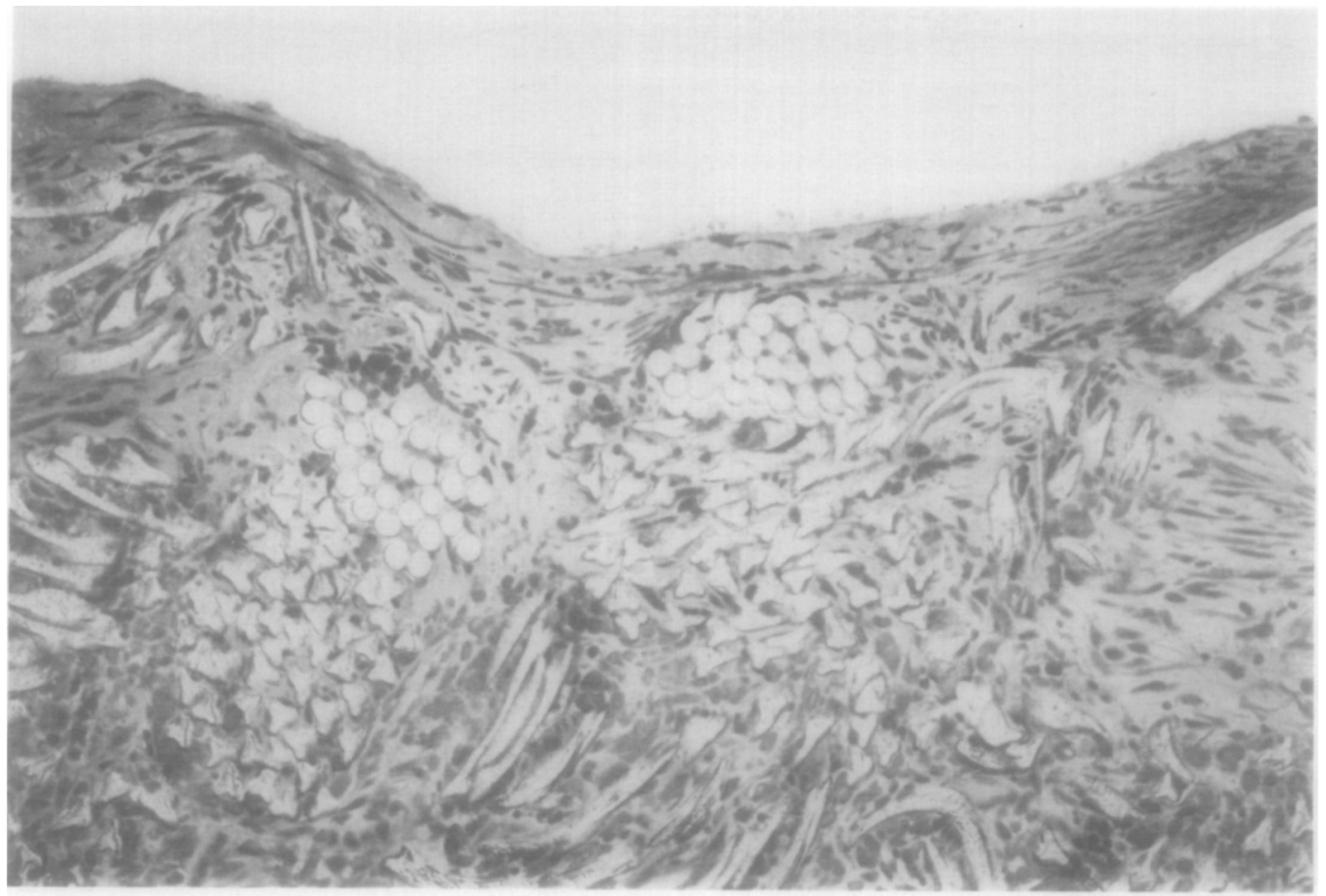

Fiv. 10. Section of one of the better areas of a 14-day control graft showing good incorporation and infiltration of tissue from the perigraft tissue. The lining, while thin, is composed of fibrin, platelets, and occasional WBCs (see Fig. 17) $(\times 140)$.

being thicker in the valleys and thinner over the apices of graft crimps. The thick fibrin coagulum seen on the surface of control grafts, and some unhealed areas of the experimental grafts revealed a layering characteristic of Dacron grafts (Fig. 10). It was composed of fibrin, platelets, and elongated WBCs near the surface, with fibroblasts and collagenous fibers evident near the graft fibers (Fig. 11). Experimental grafts, except in a few areas such as where the graft went through the diaphragm, were grossly clean. About $60 \%$ of the graft surface was endothelialized. It was at this time in seeded grafts that total incorporation and healing were first observed (Figs. 12 and 13). The monolayer lining the graft had become mature with few surface WBCs. Additional layers of smooth muscle and fibroblasts appeared within the subendothelial region (Fig. 14). Some fibrin remained in the larger gaps between graft fibers, but this area was seemingly being organized by subendothelial tissue and cells growing out from the graft fibers (Fig. 14). In many areas grafts were totally incorporated and healed from the outer capsule to the blood surface (Fig. 15). The external regions were characterized by many large foreign body giant cells, dense connective tissue, and the ingrowth of numerous capillaries. Endothelialization of graft surfaces preceded total incorporation of its deeper layers. As the endothelium migrated over the fibrin layer, it was followed by an ingrowth of fibroblasts and smooth muscle from the adjacent healed areas. Areas lacking endothelium still had a surface composed of fibrin and platelets with WBCs.

Aside from WBCs, three types of cells were distinguishable in the healing graft. Endothelial cells covered about $60 \%$ of the surface. Smooth muscle cells were seen im- 


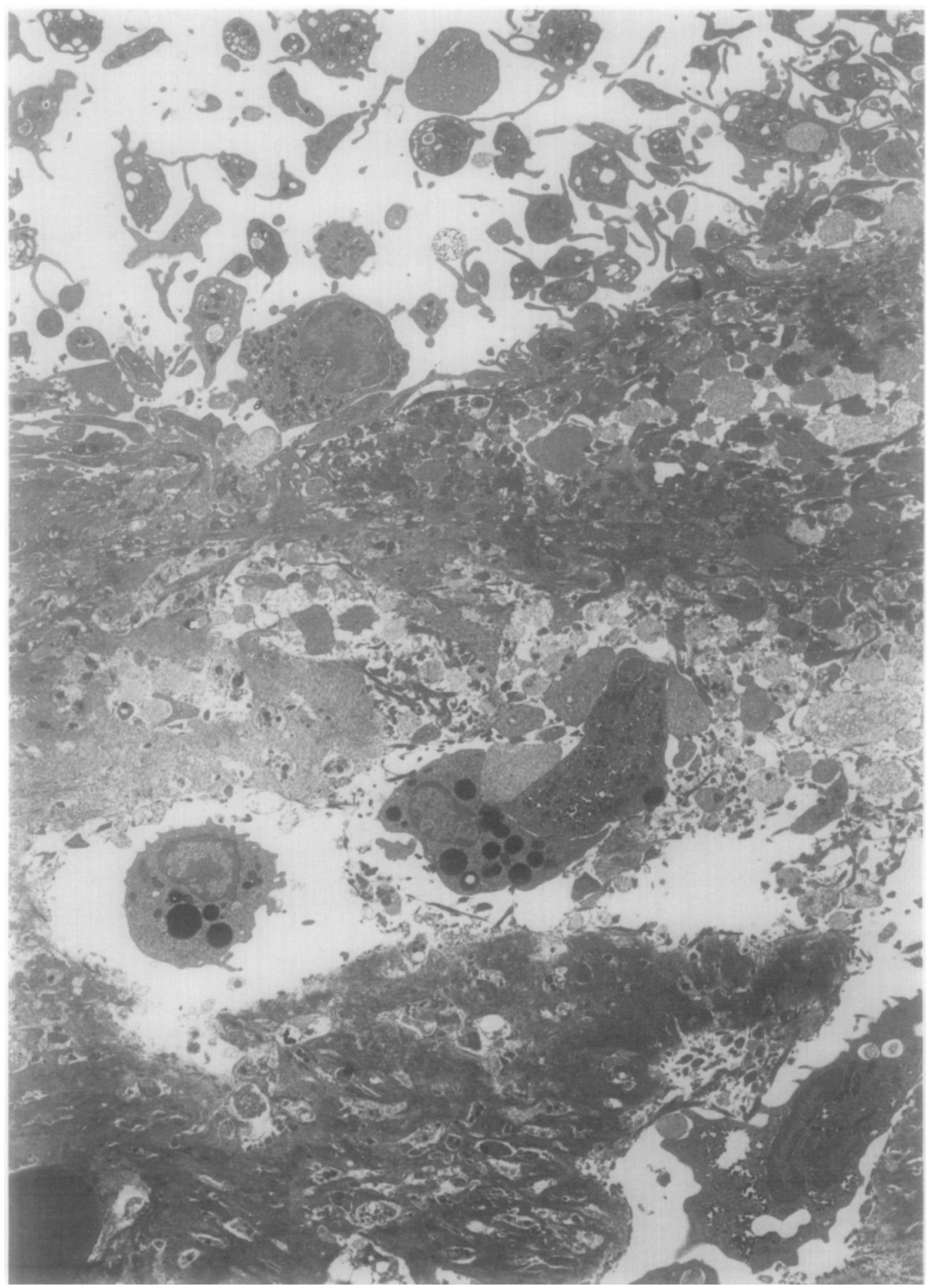

FIG. 11. Inner portion of a 7-day graft demonstrating a fibrin platelet coagulum lining the graft. The luminal surface (above) shows many activated platelets and WBCs. The zone of fibrin and platelets (middle) shows several WBCs in migration. A portion of a graft fiber may be seen in the lower left. This picture is representative of coritrol grafts at all stages after 1 day and areas of seeded grafts that have not been endothelialized (TEM $\times 4000)$. 


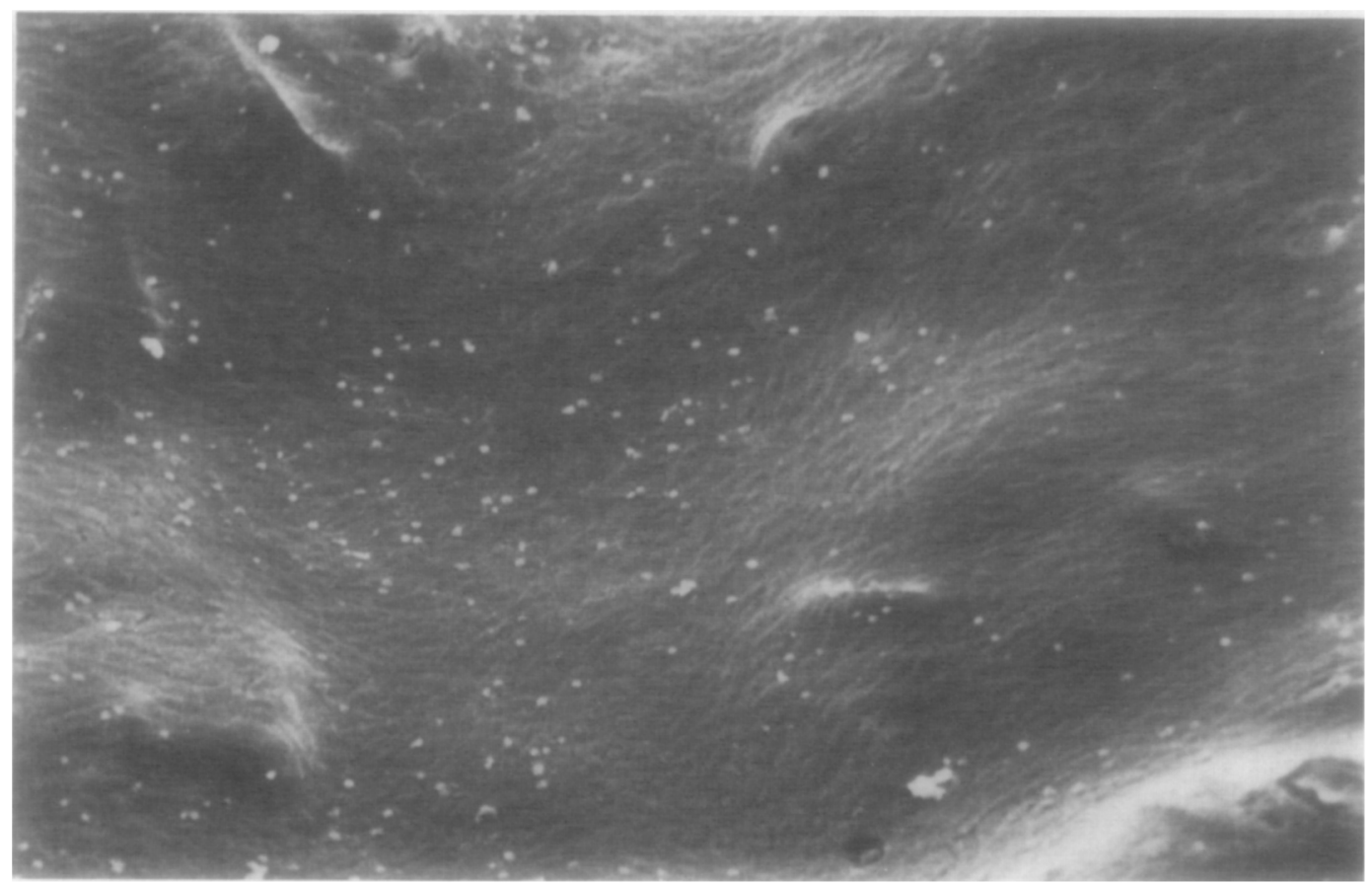

FiG. 12. Scanning electron micrograph of a 14-day seeded graft. Endothelial cells give the surface a cobblestone appearance $($ SEM $\times 140)$.

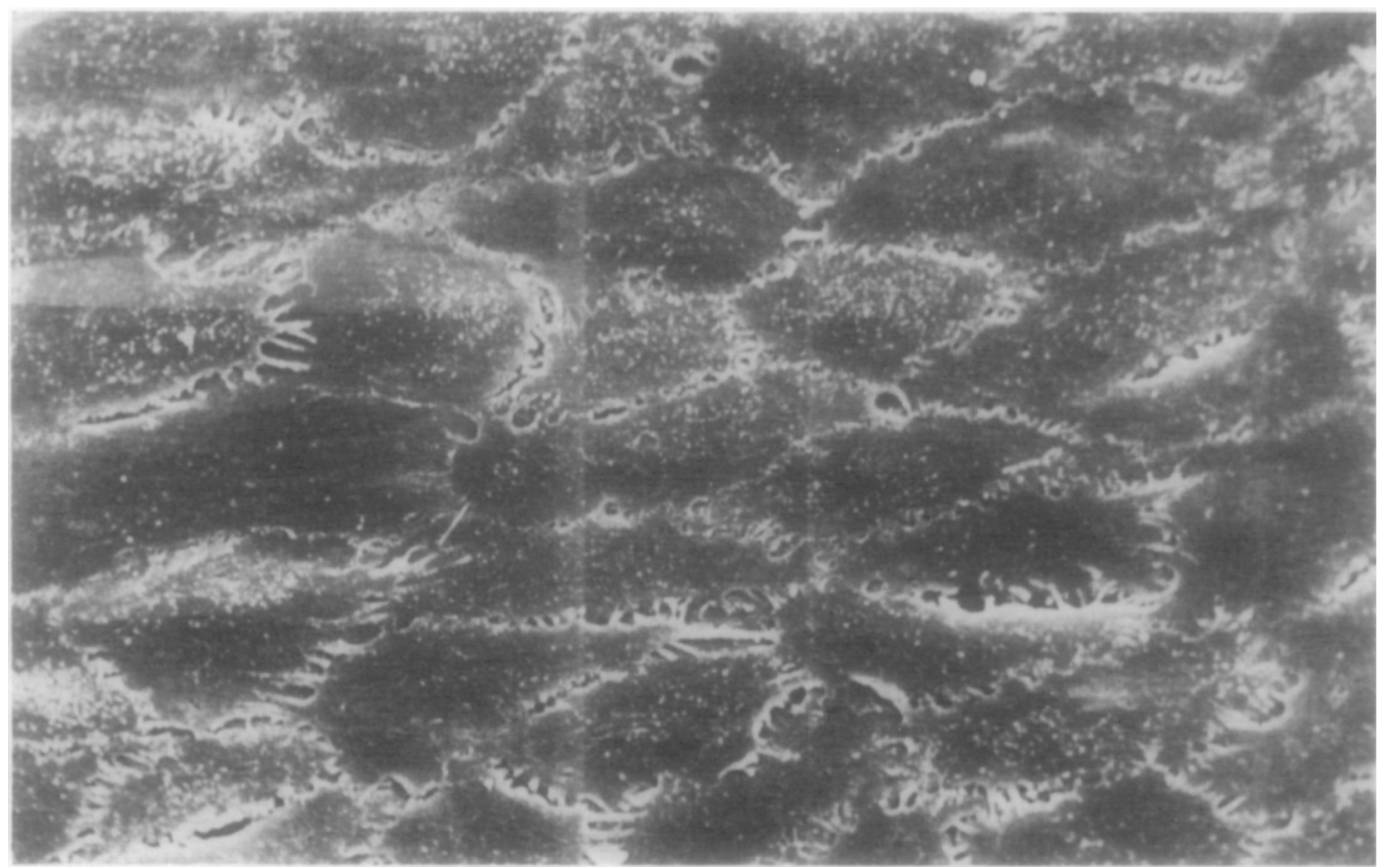

FIG. 13. Higher magnification of a portion of the graft in Fig. 12. Endothelial cells have assumed a hexagonal shape, but have not yet fully matured since small gaps are still apparent between cells $(\mathrm{SEM} \times 1500)$. 


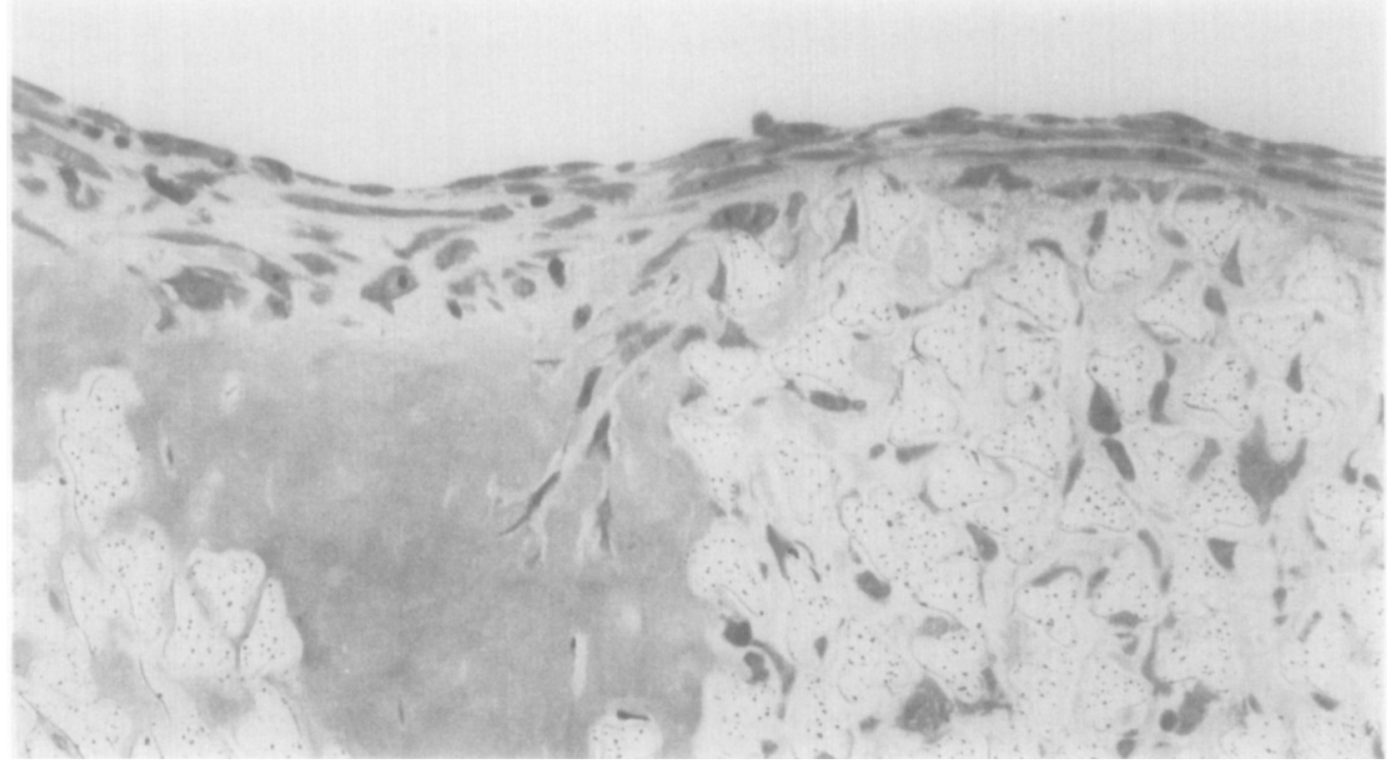

FIG. 14. A section of a 14-day seeded graft showing continued healing. Below the endothelial surface (above) layers of smooth muscle cells and fibroblasts have proliferated to fill the lysed zone seen in Fig. 6. Large areas of fibrin (center) are the last to be organized. It is not clear whether the cells migrating into the fibrin (center) are WBCs or fibroblasts. Seeded grafts heal from both the luminal surface (as shown here) and from the perigraft tissue. In contrast, control grafts (see Fig. 17) heal only from the perigraft tissue $(\times 130)$.

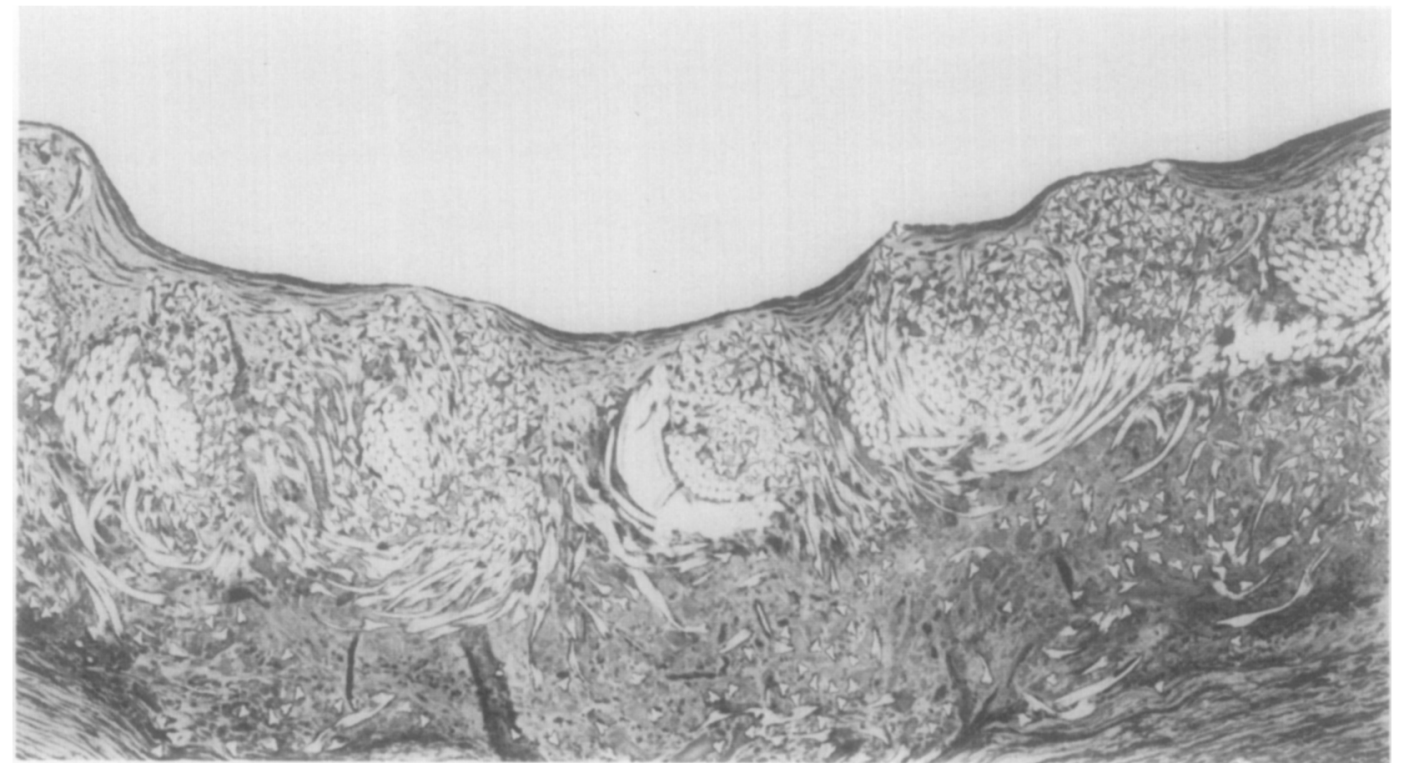

FIG. 15. Section of a 14-day seeded graft adjacent to that of Fig. 14 revealing total healing and incorporation. The graft is cellular from perigraft tissue (below) to lumen (above). The endothelium comprises a thin, complete, smooth, flow surface. The inner capsule in many areas is only one cell thick $(\times 45)$. 


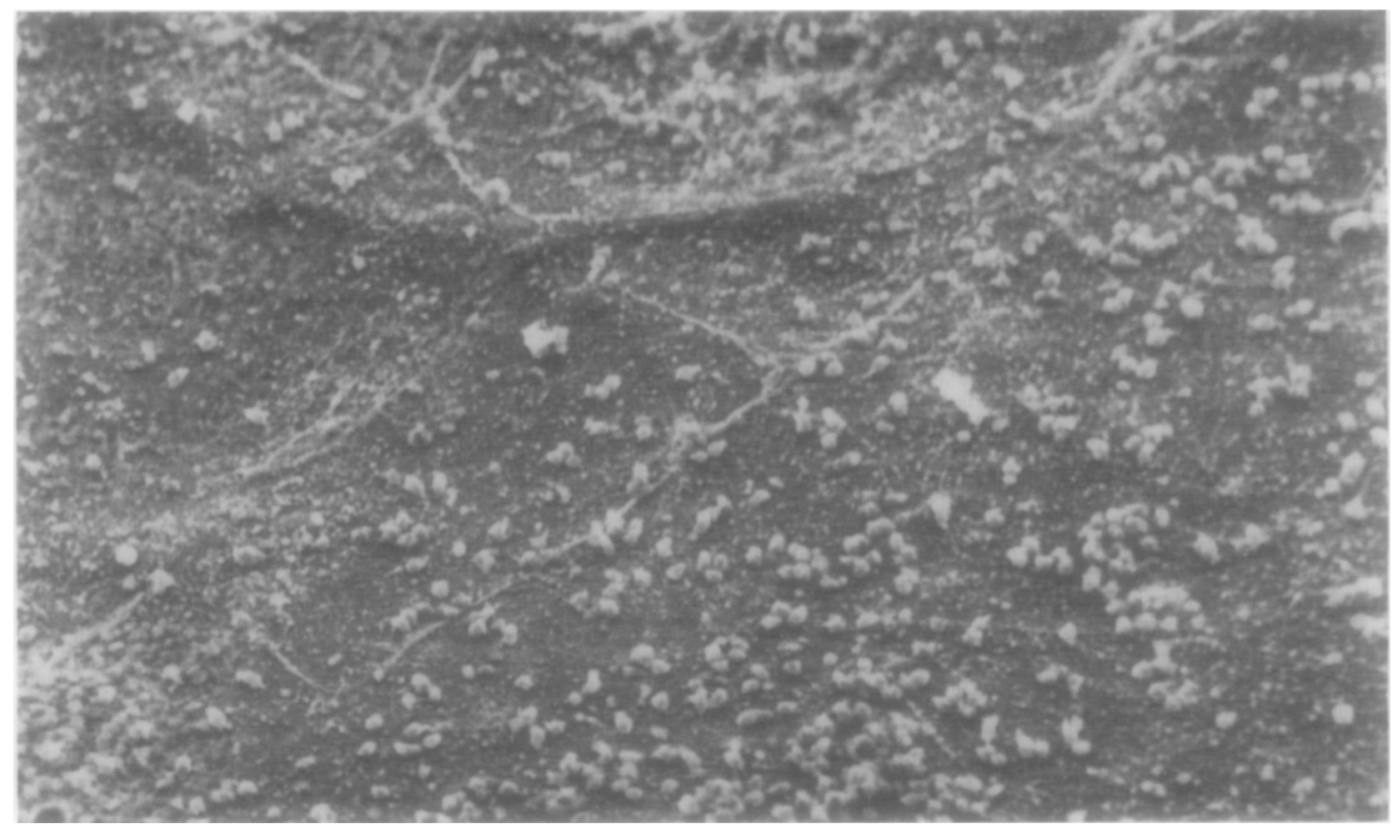

FIG. 16. Luminal surface of a control graft. Although this graft was in place 28 days, most of its flow surface is indistinguishable from grafts at 1 and 2 days. The surface is covered with WBCs, platelets, and fibrin $(\mathrm{SEM} \times 300)$.

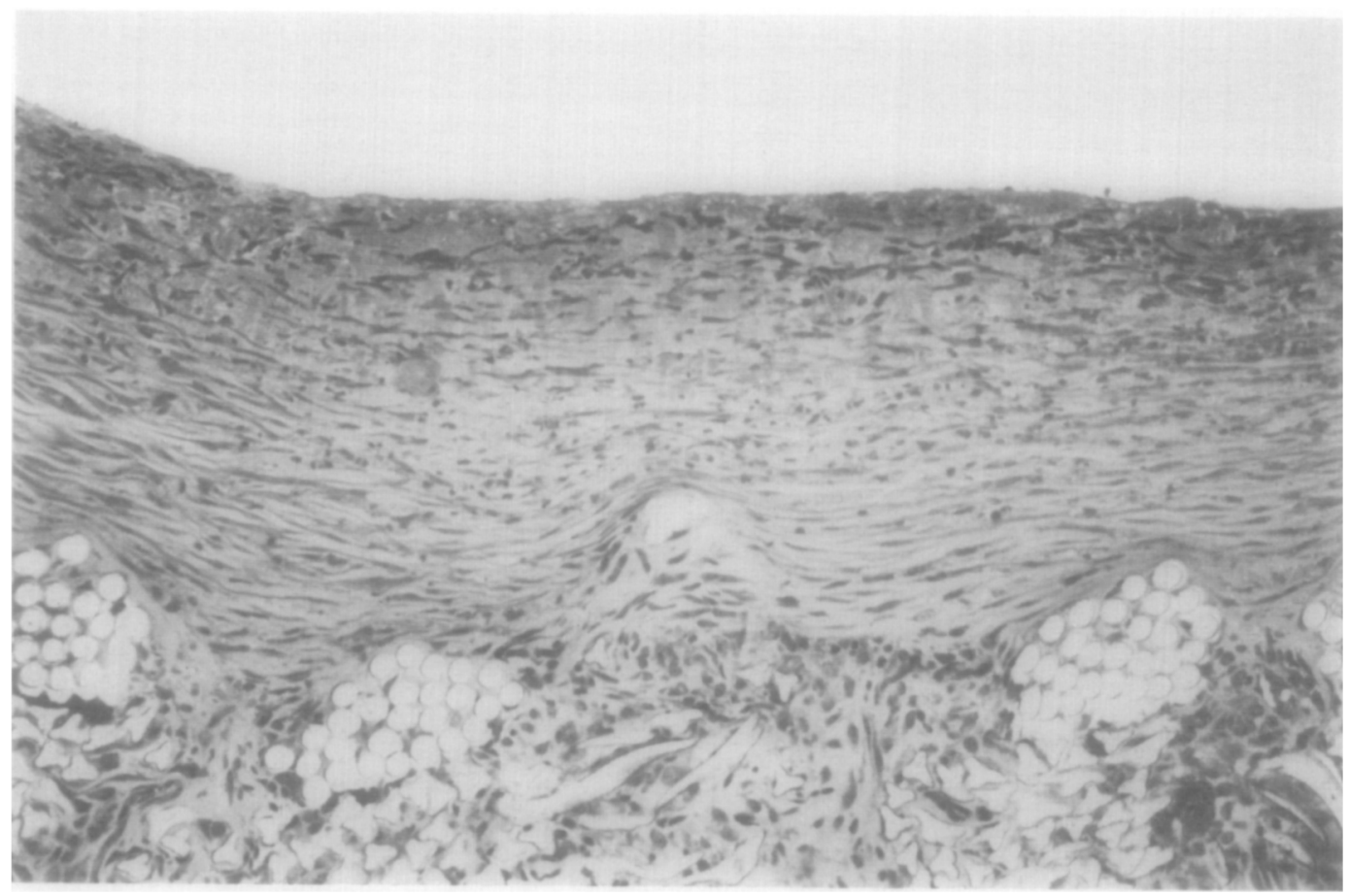

FIG. 17. Section of a 28-day control graft demonstrates the depth of the inner lining or capsule. The graft is well incorporated and has several layers of fibroblasts and collagen internal to the graft itself. The innermost 50-100 $\mu \mathrm{m}$, however, remains fibrin, platelets, and WBCs $(\times 140)$. 


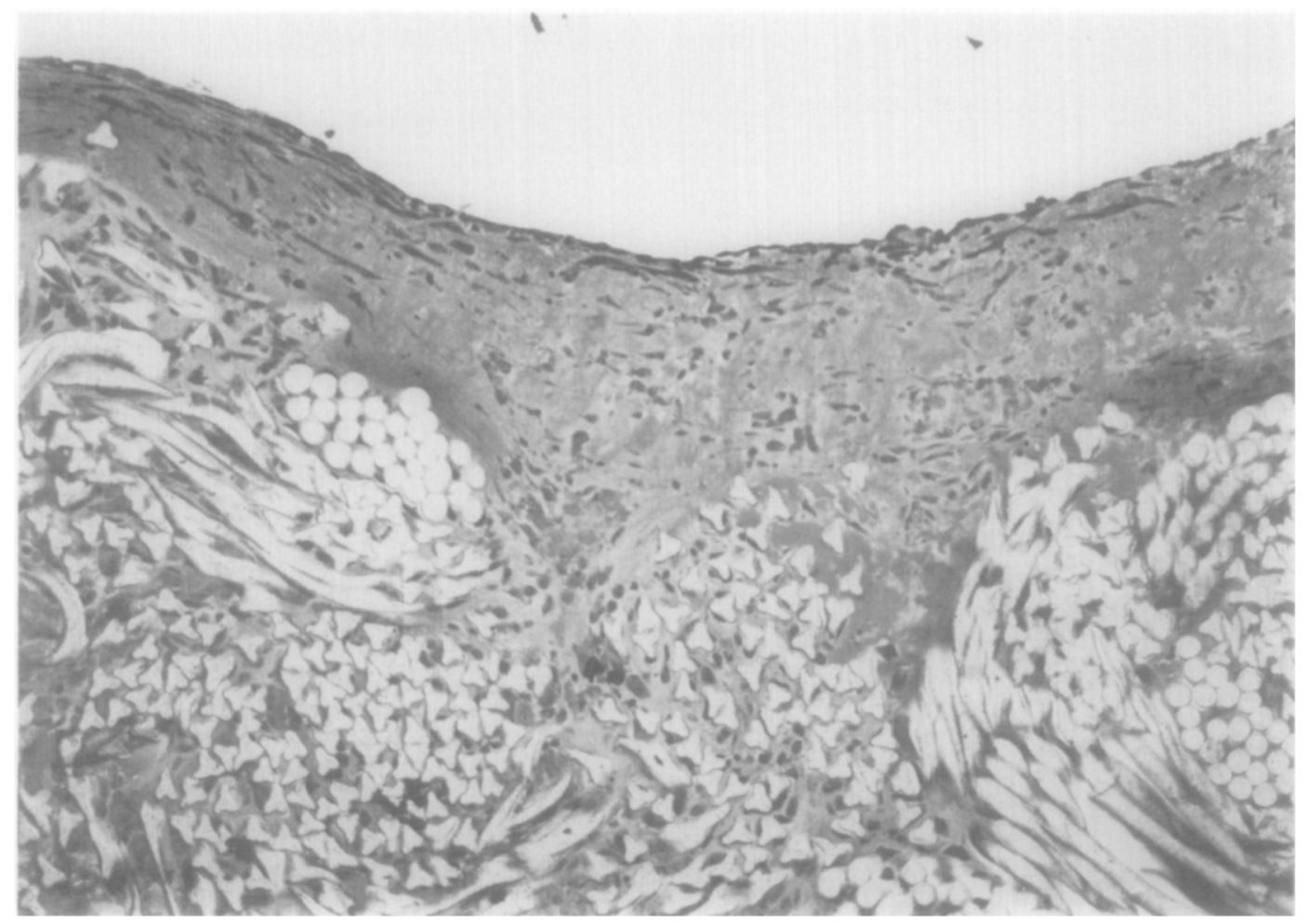

Fig. 18. Section of a 28-day control graft revealing what appears to be an endothelial surface overlying the thick fibrin-platelet coagulum. Although this region appears in many ways similar to seeded grafts, this type of healing is exceedingly rare $(\times 140)$.

mediately subjacent to the endothelium althrough their source was not clear. Deeper within the graft, fibroblasts were clearly seen migrating from the external capsule of the graft toward the lumen. They never reached the blood-contacting surface but remained deep to the endothelial or fibrin luminal lining.

Twenty-eight-day grafts. By Day 28 much of the surface thrombus apparent at Day 14 in control grafts was replaced by a layer of fibrin that appeared to be passivated to the blood. The surface appeared more stable, but varied in thickness (Figs. 16 and 17). These grafts were well incorporated in dense connective tissue at this time. Connective tissue extended within the inner graft fibers and comprised a dense layer deep to the fibrin coagulum forming the flow surface. In these grafts endothelium was generally found only at the anastomotic sites where it had grown from the host vessel. It was never found extending more than $2 \mathrm{~cm}$ from the anastomosis, covering at most $10 \%$ of the total graft surface. An exception was one control graft with an area of endothelium observed in its midregion (Fig. 18). This particular region had all of the features of a seeded graft, but the endothelium was underlain by an amount of connective tissue and fibrin greater than that seen in healed portions of seeded grafts.

Seeded grafts at 28 days were approximately $80 \%$ endothelialized, yet all phases of healing from a fibrin coagulum to a mature endothelial surface could be seen, depending upon the region examined. The endothelial cells by this time showed well-formed junctional complexes and basal laminae. Subendothelial connective tissue was com- 


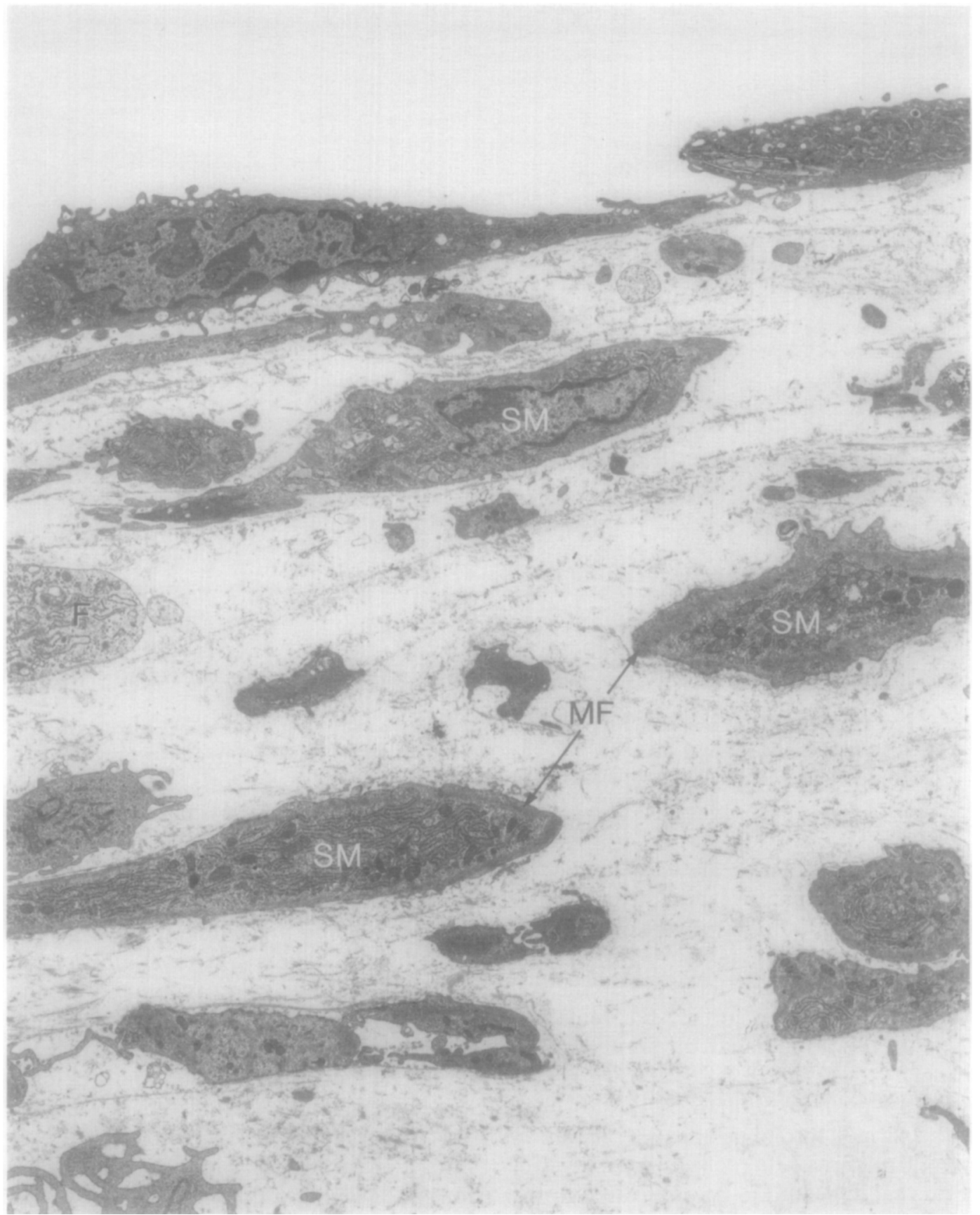

FIG. 19. Transmission electron micrograph of a 28-day seeded graft. Endothelial cells (above) form the luminal surface. They are underlain by a matrix of organizing connective tissue containing both smooth muscle cells (SM) and fibroblasts (F). The smooth muscle cells are very active and display many features of fibroblasts, but maintain the dense layer of fibrils (MF) in their peripheral cytoplasm, which clearly distinguished them from fibroblasts (TEM $\times 5700$ ).

posed of smooth muscle, collagen, and fibroblasts (Fig. 19). In less completely healed areas, smooth muscle cells looked very much like fibroblasts with extensive amounts of rough endoplasmic reticulum and many ribosomes. They were distinguishable from 


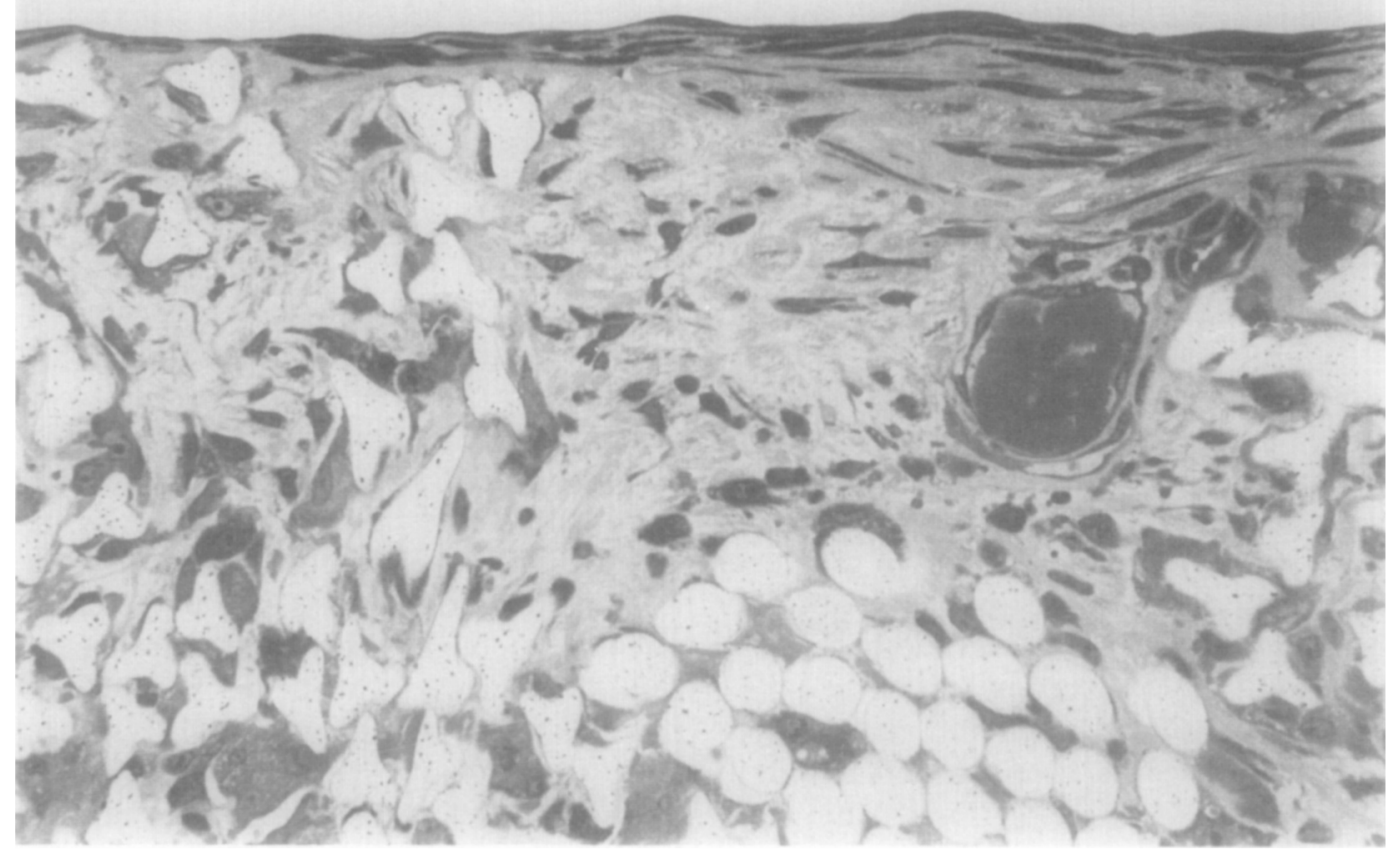

FIG. 20. Section of a 28-day seeded graft. A thin, monolayer of endothelial cells underlain by spindleshaped smooth muscle cells forms the flow surface. Pleomorphic fibroblasts and collagenous fibers predominate in the deeper graft. A large venule and smaller arteriole (right) are seen close to the lumen. Vessels such as these have been observed opening into the lumen of the graft $(\times 450)$.

fibroblasts by large numbers of intracellular fibrils, pinocytotic vesicles, and patches of basal lamina that enlarged as cells became less active. Although in many ways these cells appear like fibroblasts it is clear that they represent only a modulated state of typical smooth muscle. Fibroblasts in contrast were more pleomorphic (Figs. 19 and 20) and lacked basal lamina as well as dense intracellular fibrils and pinocytotic vesicles. At 28 days large blood vessels were seen penetrating seeded grafts. These mural vessels were frequently found within $50 \mu \mathrm{m}$ of the surface, occasionally with openings into the graft lumen (Fig. 20).

\section{DISCUSSION}

The thrombogenity of currently available prosthetic vascular grafts has been well documented. Despite the evolution of numerous polymers, an ideal artificial graft has not heen developed. Similarly, biological grafts, such as the bovine heterograft and umbilical vein, have not approached the performance of an autologous vein. A unique feature of autologous veins, distinguishing them from other grafts, is the presence of living smooth muscle and an endothelial lining.

Attempts to simulate endothelial flow surfaces in vitro or in vivo with artificial prostheses date to the mid-1960s. The more successful methodologies involved the use of endothelial cells to produce a pseudointima [9-11, 14].

Despite development of derivation techniques for, and widespread experimental use of, endothelium from human umbilical vein and bovine aorta, little work has been done with adult endothelium of any species. At the same time most earlier investigations were undertaken to produce pseudointimas 
from cells or tissue fragments in vitro on special surfaces such as diaphragms of artificial hearts, nonporous microfiber-lined prostheses, etc. [2]. Many of these studies had limited relevance to development of vascular conduits for use in peripheral vascular surgery.

Initially it was thought that standard Dacron grafts of even the finest fibers were too rough and had "pores" too large for endothelial cells to bridge [4]. Therefore the generation of pseudointimas by seeding standard grafts was not seriously pursued. The demonstration by Herring and his colleagues that endothelial cells could be seeded in standard grafts during preclotting, followed by immediate implantation, provided a new approach to the problem [11]. We had previously tried seeding endothelial cells into clot-lined, nonporous microfiber prostheses to produce pseudointimas in vitro with little success (unpublished results). However, when done with immediately implanted standard grafts seeding produced a dramatic acceleration of graft incorporation.

Healing of prosthetic vascular grafts has been described by numerous investigators $[1,5,13,16-18,21-23]$. The important features of this process were described early by MacKenzie and Lowenthal [12]. They documented four stages of graft healing: (1) deposition of fibrin, cells, and platelets, (2) granulation tissue reaction, (3) organization of fibrin by way of growth from perigraft tissues and pannus ingrowth, and (4) endothelization of the graft from the aorta of the host. Our findings in control grafts are in agreement with their description, with the exception of certain instances of endothelial cells found in the midgraft regions. Seeding of endothelial cells into graft interstices as part of a preclot process provides another front for tissue growth, and was a major factor contributing to the rapid healing observed in our experiments.

Healing processes in seeded grafts involve not only the endothelial surface, but also cellular growth about the graft in its entirety. This occurred as early as 14 days in some areas, and was evident in all regions by 28 days. Although nearly all cells seeded into grafts were endothelial cells [10], it is important to note that the subintimal tissue was composed of several layers of smooth muscle cells. Fibroblasts were found only within the immediate region of graft fibers and in the perigraft tissue. Since only a small number of smooth muscle cells were in the seeding inoculum the question arises as to their origin.

Several potential sources of smooth muscle exist, including: (1) transformation of some other cell type, such as fibroblasts, endothelial cells, or blood cells, (2) rapid proliferation of the original inoculum, (3) ingrowth from perigraft connective tissue, and (4) rapid pannus ingrowth from the aorta. Despite numerous suggestions in the literature that smooth muscle may arise from other cell types, there is no definitive evidence that this phenomenon occurs. Cells resembling both smooth muscle and fibroblasts by the light microscope appear to be only modulations of normal smooth muscle when examined with the electron microscope. Many of these cells become proliferative, produce collagen, and assume certain features of fibroblasts. This modulation is most obvious in the transition zone between the graft and the host aorta. As smooth muscle cells migrate into the graft they appear very much like fibroblasts even at the electronmicroscopic level. As the graft wall becomes organized, these cells form gap junctions as well as basal lamina, and revert to typical smooth muscle morphology. It is most probable that depending on the region of the graft involved smooth muscle cells arise from contamination of the original inoculum and/or from pannus and perigraft ingrowth.

A related question addresses the fate of the seeded endothelial cells. Presumably many of these cells initially lie deep within the graft interstices. Whether all of them migrate to the luminal surface to form the pseudointima, or if some become entrapped in the graft fibers is unknown.

That the endothelial inoculum gives rise to the lining covering the luminal surface appears clear. The difference between seeded 
and unseeded grafts was dramatic. The source of endothelial cells seen in the midregion of the unseeded graft is more problematic. This phenomenon, observed by numerous investigators, was first reported by Florey and coworkers, who associated these cells with capillaries penetrating the graft [5]. Other proposed potential sources of endothelium have included: transformed monocytes, fibroblasts or smooth muscle, and pannus. Despite speculation on transformation of cells into endothelium there is no convincing evidence that endothelium arises from anything other than endothelial cells. Because a definitive marker at the light-microscope level for endothelium, such as factor VIII fluorescence, was lacking until recently, many earlier reports of endothelial graft linings are subject to question.

If endothelium arises only from endothelium then its sources narrow down to: (1) capillaries penetrating the graft, (2) pannus ingrowth, and (3) endothelial cells circulating in the blood itself. It is conceivable that capillaries in the inner capsule of grafts may become exposed if a portion of pseudointima is sheared off, or embolized. It is not unreasonable to assume that such exposed endothelial cells would proliferate and provide coverage of a portion of the graft, similar to the process that occurs around orifices of intercostal vessels in denuded aortas [20].

The probability of endothelium growing from the aorta to the midgraft region of a $30-\mathrm{cm}$-long graft in 14 to 28 days is small, since the maximum extent of pannus ingrowth was only $2 \mathrm{~cm}$ in control grafts. Endothelialization has been estimated to proceed at rates ranging from 0.1 [12] to $3.0 \mathrm{~mm}$ [8] per day in dogs. Thus pannus ingrowth could not be totally excluded in 28-day controls, although a lack of endothelium anywhere within several centimeters of endothelial cell patches in the midgraft regions argues against this source. However, differences in graft designs and healing rates among various species [19] greatly affect the data reported and extrapolating results from one group of investigators to another is difficult.
Lastly, it is conceivable that endothelial cells circulating in the blood might find a hospitable environment on the graft surface should they lodge there. It is known that endothelial cells are sloughed from vessels, particularly where turbulent flow might be expected [24]. A potential source may be the proximal aorta where it has been traumatized by vascular clamps or other manipulations during the implantation process. Detachment of endothelial cells from vessels during such manipulations has been documented [7], and "fall out healing" has been suggested by others [1].

Data presented in the present investigation clearly document the advantage of seeding endothelial cells into Dacron grafts in enhancing their incorporation and healing. Since pannus ingrowth of endothelium in man is of limited extent and rarely leads to total healing of the graft, the potential usefullness of endothelial cell seeding is very important. While clinical application of these techniques has not yet been reported, these experiments suggest that the performance of grafts may be significantly improved by endothelial cell seeding, and this may permit the application of artificial vessels in situations where they are now used only with considerable risk.

\section{ACKNOWLEDGMENTS}

This investigation was supported in part by National Heart Lung and Blood Institute Contract N01-HV-2054 and Grant HL23345. The authors gratefully acknowledge the technical assistance of $\mathbf{J}$. W. Crudup (Department of Surgery) and R. Sell and J. Dean (Department of Anatomy).

\section{REFERENCES}

1. Berger, K., Sauvage, L. R., Rao, A. M., and Wood, S. J. Healing of arterial prostheses in man: Its incompleteness. Ann. Surg. 175: 118, 1972.

2. Burkel, W. E., and Kahn, R. H. Cell-lined, nonwoven microfiber scaffolds as a blood interface. Ann. N. Y. Acad. Sci. 283: 419, 1977.

3. Burkel, W. E., Ford, J. W., and Kahn, R. H. Derivation of adult venous endothelium. In Vitro 15: $215,1979$.

4. Eskin, S. G., and Trevino, L. Aortic endothelial cells and smooth muscle cells cultured on cardio- 
vascular biomaterials. Scanning Electron Microsc. 2: $209,1976$.

5. Florey, H. W., Greer, S. J., Poole, J. C. F., and Werthessen, N. T. The pseudointima lining fabric grafts of the aorta. Brit. J. Exp. Pathol. 42: 236, 1961.

6. Ford, J. W., Burkel, W. E., and Kahn, R. H. Isolation of adult canine venous endothelium for tissue culture. In Vitro 17: 44-50, 1981.

7. Gertz, S. D., Rennels, M. L., Forbes, M. S., Kawamura, J., Sunaga, 'I'., and Nelson, E. Endothelial cell damage by temporary arterial occlusion with surgical clips. Study of the clip site by scanning and transmission electron microscopy. J. Neurosurg. 45: 514, 1976.

8. Ghidoni, J. J., Liotta, D., Hall, C. W., Adams, J. G., Lechter, A., Barrionueva, M., O’Neal, R. M., and DeBakey, M. E. Healing of pseudointimas in velour-lined, impermeable arterial prostheses. Amer. J. Pathol. 53: 375, 1968.

9. Graham, L. M., Burkel, W. E., Ford, J. W., Vinter, D. W., Kahn, R. H., and Stanley, J. C. Immediate seeding of enzymatically derived autologous canine endothelium in Dacron velour vascular grafts. Arch. Surg. 115: 1289-1294, 1980.

10. Graham, L. M., Vinter, D. W., Ford, J. W., Kahn, R. H., Burkel, W. E., and Stanley, J. C. Endothelial cell seeding of prosthetic vascular grafts: Early experimental studies with cultured autologous canine endothelium. Arch. Surg. 115: 929, 1980.

11. Herring, M. B., Gardner, A. L., and Glover, G. A single-staged technique for seeding vascular grafts with autogenous endothelium. Surgery 84: 498, 1978.

12. MacKenzie, D. C., and Loewenthal, J. Endothelial growth in nylon vascular grafts. Brit. J. Surg. 48: 212, 1960.

13. MacPherson, A. I. S., and Muir, A. R. Synthetic fabric prostheses implanted 1 to 6 years: Studies by light and electron microscopy. Scot. Med.J. 8: $262,1963$.

14. Mansfield, P. B., Wechezak, A. R., and Sauvage, L. R. Preventing thrombus on artificial vascular surfaces: True endothelial cell linings. Trans. Amer. Soc. Artif. Intern. Organs 21: 264, 1975.

15. McCune, W. S., and Blades, B. The viability of long blood vessel grafts. Ann. Surg. 134: 769, 1951.

16. Meijne, N. G. Endothelial growth in nylon vascular prostheses. Arch. Chir. Neerl. 11: 41, 1959.

17. Nomura, Y. The ultrastructure of the pseudointima lining synthetic arterial grafts in the canine aorta with special reference to the origin of the endothelial cell. J. Cardiovasc. Surg. 10: 282, 1970.

18. Sauvage, L. R., Berger, K., Beilin, L. B., Smith, J. C., Wood, S. J., and Mansfield, P. B. Presence of endothelium in an axillary-femoral graft of knitted Dacron with an external velour surface. Ann. Surg. 182: 749, 1975.

19. Sauvage, L. R., Berger, K. E., Wood, S. J., Yates, S. G., II, Smith, J. C., and Mansfield, P. B. Interspecies healing of porous arterial prostheses. Arch. Surg. 109: 698, 1974.

20. Schwartz, S. M., Haudenschild, C. C., and Eddy, E. M. Quantitative analysis of initial stages of endothelial regeneration in rat aortic intima. $L a b$. Invest. 38: 568, 1978.

21. Shimamura, T., Fyorkey, F., Kawakami, T., Beall, A. C. Jr., and DeBakey, M. E. The ultrastructure of neointima of canine infrarenal vena caval teflon prostheses. Exp. Mol. Pathol. 13: 190, 1970.

22. Stewart, G. J., Essa, N., Chang, K. H. Y., and Reichle, F. A. A scanning and transmission electron microscope study of the luminal coating on Dacron prostheses in the canine thoracic aorta. J. Lab. Clin. Med. 85: 208, 1975.

23. Wesolowski, S. A. Performance of materials as prosthetic blood vessels. Bull. N. Y. Acad. Med. 48: $331,1972$.

24. Wright, H. P. Endothelial turnover. In Vascular Factors and Thrombosis. Stuttgart; Schattauer, 1970. P 79.

25. Yates, S. G., Barros D'Sa, A. A. B., Berger, K. E., Fernandez, L. G., Wood, S. J., Rittenhouse, E. A., Davis, C. C., Mansfield, P. A., and Sauvage, L. R. The preclotting of porous arterial prostheses. Ann. Surg. 188: 611, 1978. 